Arab Univ. J. Agric. Sci., Ain Shams Univ., Cairo, 14(2), 835-844, 2006

\title{
RECOGNITION OF CERTAIN KAIROMONES BY THE PARASITOID TRICHOGRAMMA SPP. IN EGGS OF IT'S HOST CYDIA POMONELLA
}

[54]

\author{
Sakr ${ }^{1}$, H.E.A.
}

\begin{abstract}
A kairomone from adult Cydia pomonella L. scales is an important factor in the host recognition and searching behaviour process of Trichogramma cacoeciae Marchal and Trichogramma dendrolimi Matsumura. The Trichogramma spp. used the chemicals from the host eggs for orientation to host and increased their parasitism. The females of $T$. cacoeciae $^{*}, T$. dendrolimi** and $T$. dendrolimi*** contacted the unwashed host eggs significantly longer than the washed eggs. Washing the codling moth eggs with hexan significantly reduced the parasitism of all the tested Trichogramma strains compared to unwashed eggs. The treated apple trees with wing scales of $C$. pomonella had significant influence on the parasitism compared to untreated trees. The percentage parasitism of codling moth eggs on the treated trees $(31.6 \%)$ was significantly higher than on the untreated trees $(19.3 \%)$.
\end{abstract}

Keywords: Trichogramma cacoeciae, T. dendrolimi, Cydia pomonella, Kairomone, Wing scales, Recognition, Searching behaviour, Parasitism

\section{INTRODUCTION}

Kairomones are used by parasitoid as cues for orientation to their host habitat, location and recognition during host selection (Noldus, 1989). The stage of host selection at which a female parasitoid uses kairomones depends upon the degree of her host specialisation (Vet and Dicke, 1992). The sources of kairomones used by Trichogramma spp. for host and host habitat location include sex pheromones and wing scales of host moths (Noldus, 1989; Noldus et al 1990; Ananthakrishnan et al 1991).

1- Department of Plant Protection, Faculty of Agriculture, Ain Shams University, Shoubra El-Kheima, Cairo, Egypt

* A strain collected from Germany 1990 and reared in Institute for Biological control, Darmstadt, Germany.

** A strain collected from China 1984 and reared in Institute for Biological control, Darmstadt, Germany.

*** A strain collected from Germany 1990 and reared in Institute for Biological control, Darmstadt, Germany.

(Received April 4, 2006)

(Accepted May 18, 2006) 
Several studies demonstrated that the wing scales of host moths play an important role in the searching locomotion of Trichogramma females. Noldus and van Lenteren (1983 and 1985) reported that the wing scale of Pieris brassicae L., P. rapae L., and Mamestra brassicae L. contained a contact kairomone leading to arrestment of $T$. evanescens Westwood. Females of $T$. evanescens sought significantly longer on cabbage leaves treated with the wing scale of two hosts, $P$. brassicae and $P$. rapae. Also, the egg washes of $P$. brassicae had a contact-kairomonal effect on the parasites.

Recognition of specific kairomones was also acquired by learning, through the association of the host and its kairomones during oviposition (Alphen and Vet, 1986). Huang and Gordh (1998) tested the oviposition behaviour of female T. australicum Girault on host eggs and glass beads and found that females did not depend on chemical cues to recognize their host eggs.

The effect of kairomones on the searching capacity of three Tricho-


drolimi $^{* *}$ and $T$. dendrolimi $* * *$ to parasitize host eggs of Cydia pomonella L. was studied by a laboratory host preference test with washed and unwashed host eggs. Also, a semi-field test was conducted, using small apple trees planted in plots, which were treated with $C$. pomonella wing scales.

\section{MATERIAL AND METHODS}

Cydia pomonella as a host insect and three strains of Trichogramma parasitoids, T. cacoeciae $^{*}, T$. dendrolimi ${ }^{* *}$ and T. dendrolimi ${ }^{* * *}$ were successfully mass

$*, * *, * * *$ see footnotes at p. 1 reared according to (Wührer and Hassan, 1993) at the Department of Plant Protection, Faculty of Agriculture, Ain Shams University, Egypt.

The following two experiments were conducted under laboratory conditions of $27 \pm 1{ }^{\circ} \mathrm{C}, 60$ to $80 \%$ relative humidity.

\section{Laboratory experiment}

Approximately one day old eggs laid on plastic sheet, were collected from the established $C$. pomonella culture. The eggs (on their plastic sheet) were washed by soaking them in hexan for 10 minutes and then rinsed five times in the same solvent, (Huang and Gordh, 1998). The eggs were then rinsed five times with water and then air-dried for an hour before their use in the experiment. Unwashed $C$. pomonella eggs served as the control.

The host preference and acceptance test used in this study was slightly modified from that developed by Hassan (1989). Individual Trichogramma cacoeciae* $^{*}, T$. dendrolimi** and $T$. dendrolimi $^{* * *}$ females aged approximately 24 hours, were selected from the stock culture and isolated individually in small glass tubes. To accomplish this, newly emerged adults were scattered from the rearing tubes on a white sheet of paper, they were individually captured by placing a small glass tube $(50 \mathrm{~mm}$ long and 9 $\mathrm{mm}$ in diameter), on each insect. As the parasite walked up in the tube towards a source of light, their sex could be easily determined under a binocular. The captured female was transferred into a larger experimental glass tube (100 $\mathrm{mm}$ long, 26 $\mathrm{mm}$ in diameter) that included 50 washed and another 50 unwashed eggs of $C$. pomonella, which were placed in two 
groups on opposite corners of a piece of paper measuring $25 \times 20 \mathrm{~mm}$. A droplet of honey-agar was added in the centre of the searching arena, the glass tube was closed with cloth material. The opening of the tube was sealed with black paper to prevent the insects escape and the tube was placed horizontally in a tray. The test was monitored every thirty minutes for a total period of 4 hours and the location of the female in the test tube was recorded.

After 5 days, the washed and unwashed $C$. pomonella eggs were separated and each transferred into new tubes. After emergence of Trichogramma adults and following their death they were counted as well as the number of black eggs, specifying their parasitism.

The experiment was repeated 25 times for each of the three Trichogramma strains considered.

\section{Semi-field test}

The semi-field experiment was conducted only on T. cacoeciae*. A woodenframe cage measuring 120 high, 48 wide and $60 \mathrm{~cm}$ long was prepared, three sides of the cage was covered with muslin, the fourth side as well as it's roof was covered with plastic. Small apple trees grown in pots each measuring $100 \mathrm{~cm}$ in height, was placed in each cage. $C$. pomonella wing scales were collected from their moths and applied, by means of a camel hair brush, on the tree stem and up to the branches and leaves bearing the host eggs. Five newly deposited codling moth egg masses, with an average of 10 eggs each, were placed on the apple tree leaves upper surface.

T. cacoeciae adults were released by placing a glass tube $(100 \times 26 \mathrm{~mm})$ containing an average of 1500 females on the floor of the cage. The host eggs were collected and removed after 2, 4 and 6 days from exposure to the Trichogramma adults and replaced with the same number of $C$. pomonella newly laid egg masses. The collected eggs were incubated at $25^{\circ} \mathrm{C}$ and $70-80 \%$ relative humidity until they turned black and rate of parasitism determined. The experiment lasted six days and was replicated three times. The same experiment was conducted but without the application of $C$. pomonella wing scales, to represent the control.

\section{Data analysis}

The data of laboratory glass tube test on parasitism and emergence were analysed using generalised Model (PROC GLM), SAS Institute, (1996). The contact time of the parasitoids with host eggs was analysed using Chi- Square test (SAS, 1996).

The semi-field data were subjected to analysis of variance (ANOVA) using the Linear Models (GLM) procedure (SAS Institute, 1996). Data of percentage parasitism was transformed (arcsine) for the ANOVA (Sokal and Rohlf, 1981 and Scheiner, 1993).

\section{RESULTS AND DISCUSSION}

\section{Laboratory experiment}

The results of the glass tube test to determine the preference of Trichogramma to hexan washed or unwashed C. pomonella eggs are shown in Figures 1, 2 and 3.

The females of the three species $T$. dendrolimi** $^{*}, T$. cacoeciae* or $T$. dendrolimi $^{* * *}$, contacted the washed host eggs of $C$. pomonella significantly less by $9.5,6.5$ and $4.5 \%$ respectively than on 


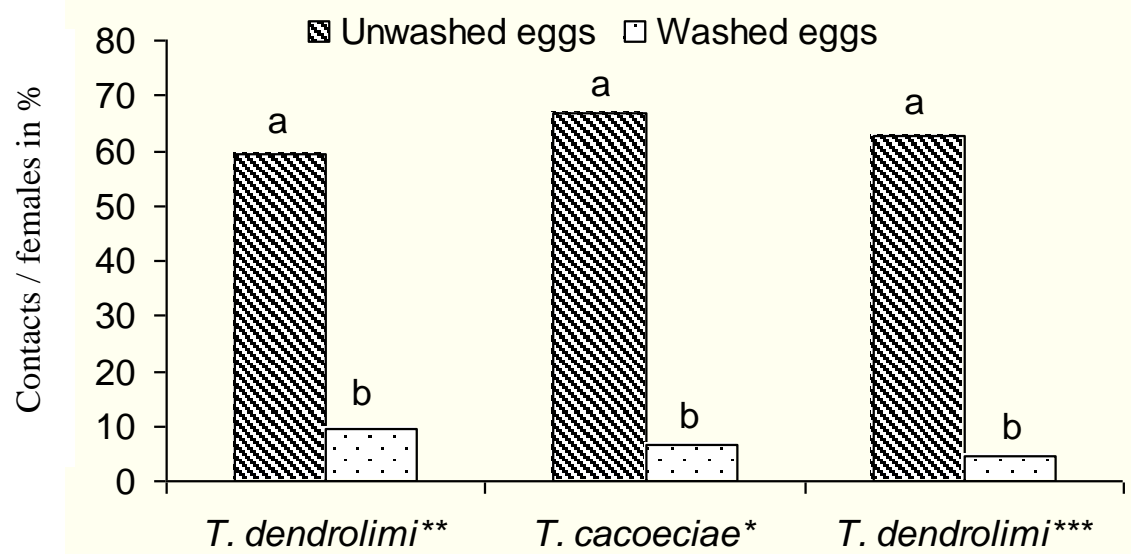

Figure 1. Frequency of contacts in 8 observations of three Trichogramma strains when offered the choice between hexan washed and unwashed eggs of Cydia pomonella

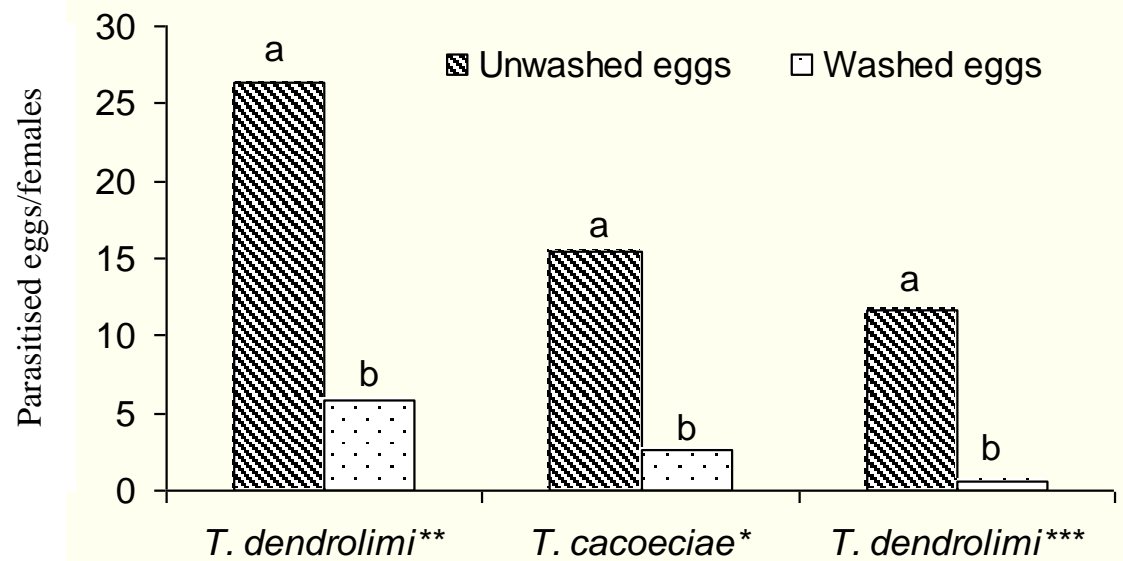

Figure 2. Frequency of parasitism of three Trcichogramma strains when offered the choice between hexan washed and unwashed eggs of Cydia pomonella 


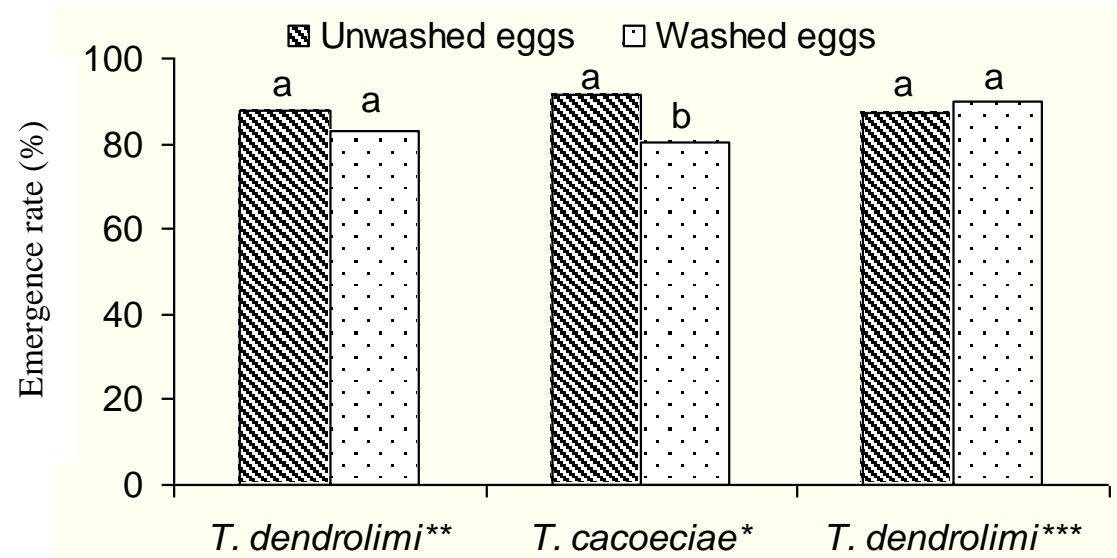

Figure 3. Emergence rate of three Trichogramma strains out of hexan washed and unwashed eggs of $C$. pomonella

unwashed host eggs i.e. 59.5, 67.0 and $62.5 \%$ respectively, $(\mathrm{F}=442.73)$ (Figure 1).

Washing $C$. pomonella eggs with hexan also significantly reduced parasitism by all three Trichogramma species. The rate of parasitism was found to be 5.8, 2.7 and 0.6 by $T$. dendrolimi**, $T$. dendrolimi $^{* * *}$ and T. cacoeciae*, respec- $^{*}$ tively as compared to parasitism on unwashed eggs, i.e. (26.4, 15.4 and 11.7 respectively) to the three respective mentioned Trichogramma species $(\mathrm{F}=224)$ (Figure 2).

No significant differences were found in the rate of adult emergence of the three considered strains of Trichogramma in hexan washed and unwashed of $C$. pomonella eggs $(\mathrm{F}=1.32)$ (Figure 3$)$.

\section{Semi-field experiments}

Small pillar apple trees treated with the wing scales of the host moth $C$. pomonella significantly increased parasitism by $T$. cacoeciae* on codling moth eggs, reaching $31.6 \%$ as compared to $19.3 \%$ parasitism on eggs placed on trees not treated with moth scales, [Table 1 (F $=6.36$ ) and Figure 4].

Table 1. Statistical analysis of searching capacity on $T$. cacoeciae* $^{*}$ to parasitize $C$. pomonella eggs on apple trees treated and untreated with $C$. pomonella wing scales

\begin{tabular}{|lccc|}
\hline Source of variation & df & F value & $\mathrm{P}$ \\
\hline Wing scales & 1 & 6.36 & .0136 \\
Time & 2 & 56.16 & .0001 \\
Wing scales *time & 2 & 4.22 & .0180 \\
\hline
\end{tabular}




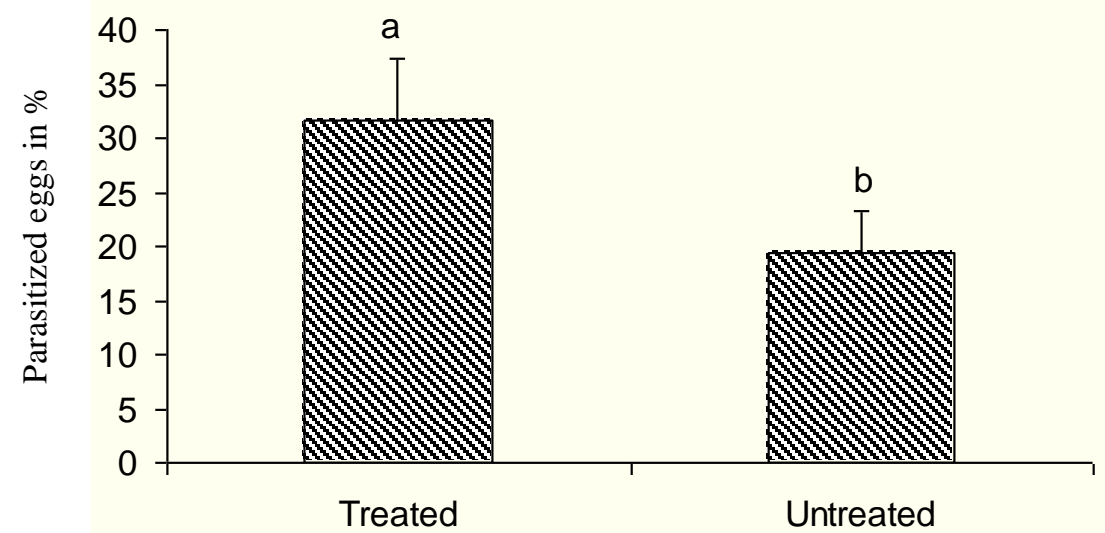

Figure 4. Parasitism (\%) by Trichogramma cacoeciae* using codling moth Cydia pomonella eggs on single potted apple trees treated and untreated with wing scales in cage.

As exhibited in Figure 5, percentage of parasitism was highest during the first two days following release reaching 75.3 $\pm 8.0 \%$ and $44.0 \pm 5.6 \%$ on $C$. pomonella eggs placed on trees treated with wing scales and untreated trees, respectively. Egg parasitism gradually decreased in the following days to reach 16.7 and $2.7 \%$ on the fourth and sixth day, respectively, following $T$. cacoeciae release on treated trees. This percentage was 14.0 and $0.0 \%$ to the respective mentioned days for $C$. pomonella eggs placed on trees not treated with the moth wing scales.

Although at the three inspection periods rate of parasitism was always higher in $C$. pomonella eggs in trees treated with codling moth wing scales, this difference was only significant at the first inspection i.e. two days following release. At the following two inspections the difference was non significant.

\section{DISCUSION AND CONCLUSIONS}

In general, Trichogramma spp. are polyphagous parasitoids and appear to recognise their hosts by using physical features rather than host specific recognition kairomones (Schmidt, 1994), which are used by other genera of oligophagous parasitoid wasps (Strand \& Vinson, 1982, 1983; Bin et al 1993). Few studies suggest that chemical cues might promote or inhibit host acceptance by some Trichogramma spp. (Nordlund et al 1987).

The chemical factors that Trichogramma spp. depend on to recognise their host vary among species in the genus. About $47 \%$ of the female $T$. australicum 


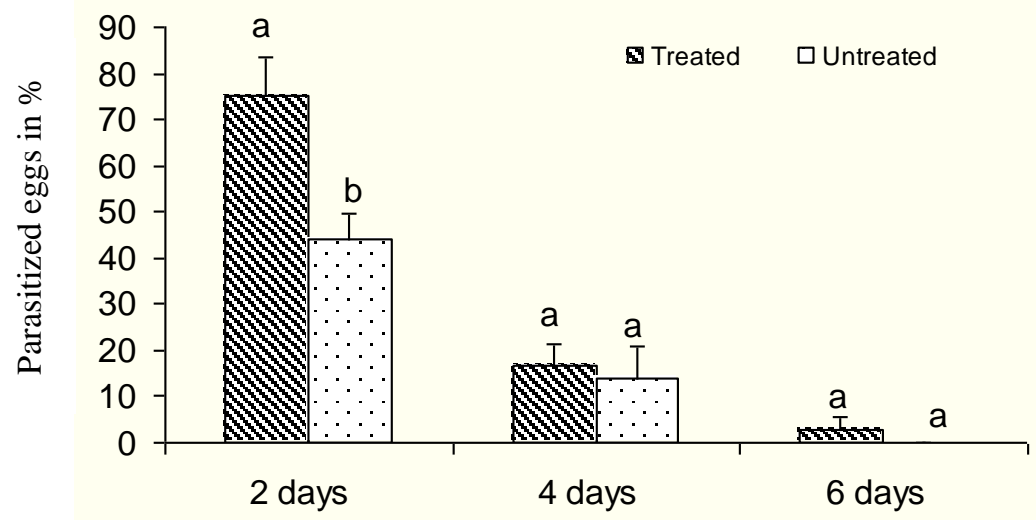

Figure 5. Percentage of parasitism by $T$. cacoeciae* $^{*}$ on $C$. pomonella eggs placed on treated with wing scales of the moth and untreated trees after different intervals from release

females attempted to drill on clean glass beads (Huang \& Gordh, 1998), only $18 \%$ of Trichogramma pretiosum Riley females accepted clean glass beads lacking an accessory gland secretion recognition. The acceptance of the wasps increased to $60 \%$ when the beads were treated with accessory gland secretion (Nordlund et al 1987).

Results of the present work showed that three Trichogramma strains T. dendrolimi**, $^{*}$, . dendrolimi***, and $T$. cacoeciae* $^{*}$ were able to recognise chemicals from their host $C$. pomonella eggs as depicited by an increased rate of parasitism. Females of these three Trichogramma strains contacted unwashed host eggs significantly longer than hexan washed eggs. Washing the codling moth eggs with hexan significantly reduced parasitism. In a similar study, Noldus and van Lenteren (1983 and 1985) showed that $T$. evanescens females sought significantly longer on cabbage leaves sprayed with a methanol or water wash of $P$. brassicae eggs than on leaves treated with solvent only. However, Huang and Gordh (1998) indicated that washing $H$. armigera eggs with various organic solvents or immersing eggs for 1 $\mathrm{h}$ in deionised water had no effect on the acceptability of T. australicum females.

Among the kairomones that Trichogramma wasps use as cues for host location are wing scales of the host moth. The results of this study showed the positive effect of the wing scales of the codling moth on the parasitism of $T$. cacoeciae*, on this moth eggs. Noldus and van Lenteren (1983 and 1985), reported the contact-kairomonal effects of wing scales of Mamestra brassicae for T. evanescens as a significant higher number of landings occurred on treated leaves. Lewis et al (1975) indicated the ability of fieldapplied tricosane, a compound identified from the scales of moth, to increase rates of parasitization by Trichogramma spp. 
It could be concluded that the chemical host recognition cues were beneficial to $T$. cacoeciae $^{*}$ females. The kairomone from the egg surface and the wing scales of codling moth improved the reaction of the three selected Trichogramma strains wasp to eggs of it's host $C$. pomonella.

\section{REFRENCES}

Alphen, J.J. van and L.E.M. Vet (1986). An evolutionary approach to host finding and selection. In: Waage, J.K. and D.J. Greathead (eds.), Insect Parasitoids. pp. 23-61, Academic Press, London.

Ananthakrishnan, T.N.; R. Senrayan; S. Murugesan and R.S. Annadural (1991). Kairomones of Heliothis armigera and Corcyra cephalonica and their influence on the parasitic potential of Trichogramma chilonis (Trichogrammatidae: Hymenoptera). J. Biosci. 16: 111-119.

Bin, F.; S.B. Vinson; M.R. Strand; S. Colazza and Jr W.A. Jones (1993). Source of an egg kairomone for Trissolcus basalis, a parasitoid of Nezara viridula. Physiol. Entomol. 18: 7-15.

Hassan, S.A. (1989). Selection of suitable Trichogramma strains to control the codling moth Cydia pomonella and the summer fruit tortrix moths Adoxophyes orana, Pandemis heparana (Lep.: Tortricidae). Entomophaga 34: 19-27.

Huang, K. and G. Gordh (1998). Does Trichogramma australicum Girault (Hymenoptera: Trichogrammatidae) use kairomones to recognise eggs of Helicoverpa armigera (Hübner) (Lepidoptera: Noctuidae)? Austral. J. Entomol. 37: 269-274.

Lewis, W.J.; R.L. Jines; D.A. Nordlund and A.N. Sparks (1975). Kairomones and their use for management of entomo- phagous insects: I. Evaluation for increasing rate of parasitization by Trichogramma spp. in the field. J. Chem. Ecol. 1: 343-347.

Noldus, L.P.J.J. (1989). Semiochemicals, foraging behaviour and quality of entomophagous insects for biological control. J. Appl. Entomol. 108: 425-451.

Noldus, L.P.J.J. and J.C. van Lenteren (1983). Kairomonal effects on searching for eggs of Pieris brassicae, Pieris rapae and Mamestra brassicae of the parasite Trichogramma evanescens Westwood. Meded. Fac. Landbouw., Rijksuniv. Gent 48: 183-194.

Noldus, L.P.J.J. and J.C. van Lenteren (1985). Kairomones for egg parasite Trichogramma evanescens Westwood. I. Effect of volatile substances released by two of its hosts, Pieris brassicae L. and Mamestra brassicae L. J. Chem. Ecol. 2: 781-792.

Noldus, L.P.J.J.; W.J. Lewis and J.H. Tumlinson (1990). Beneficial arthropod behaviour mediated by airborne behaviour semiochemicals: IX. Differential response of Trichogramma pretiosum, an egg parasitoid of Heliothis zea, to various olfactory cues. J. Chem. Ecol. 16: 35313544.

Nordlund, D.A.; M.R. Strand; W.J. Lewis and S.B. Vinson (1987). Role of kairomones from host accessory gland secretion in host recognition by Telenomus remus and Trichogramma pretiosum, with partial characterization. Entomol. Exp. Appl. 44: 37-43.

SAS Institute, (1996). SAS User's Guide: Statistics. SAS Institute, Cary, NC.

Scheiner, S.M. (1993). MANOVA: Multiple response variables and multispecies interactions. In: Scheiner S.M (ed.), Design and Analysis of Ecological Experi- 
ments pp. 45-55. Gurvitch, J., (ed.): Chapman and Hall, New York.

Schmidt, J.M. (1994). Host recognition and acceptance by Trichogramma. In: E. Wajnberg and S.A. Hassan (eds.), Biological control with egg parasitoids. $\boldsymbol{C A B}$ International, Oxon, UK, pp. 245-273. Sokal, R.R. and F.J. Rohlf (1981). Biometry: The principles and practices of statistics in biological research. $2^{\text {nd }}$ Ed. pp. 417-423, Freeman, New York.

Strand, M.R. and S.B. Vinson (1982). Source and characterization of an egg recognition kairomone of Telenomus heliothidis, a parasitoid of Heliothis virescens. Physiol. Entomol. 7: 83-90.
Strand, M.R. and S.B. Vinson (1983). Analysis of an egg recognition kairomone of Telenomus heliothidis (Hymenoptera: Scelionidae): Isolation and host function. J. Chem. Ecol. 9: 423-432.

Vet, L.E.M. and M. Dicke (1992). Ecology of infochemical use by natural enemies in a tritrophic context. Annu. Rev. Entomol. 37: 141-172.

Wührer, B.G. and S.A. Hassan (1993). Selection of effective species/ strains of Trichogramma (Hym.: Trichogrammatidae) to control the diamondback moth Plutella xylostella L. (Lepidoptera: Plutellidae). J. Appl. Entomol. 116: 8089. 
بحلة اتحاد الجامعات العربية للدراسات والبحوث الزراعية ، جامعة عين شمس ، القاهرة ،14(2) ، 835-844 ، 2006 دور كيرومونات فراثة دودة ثمار التفاح في التعرف على العائل والسلوك البحثي لطفيل الترايكوجراما

[54]

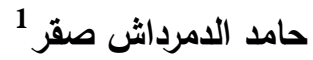 \\ 1- قسم وقاية النبات - كلية الزراعة - جامعة عين شمس - شبرا الخيمة - القاهرة - مصر لإن
}

بالمقارنة بنظيره الذي سبق غسلة بالهكسان.

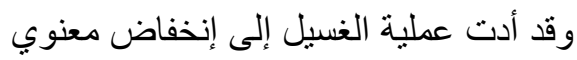

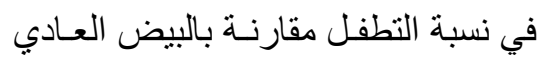

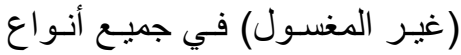
وسـلالات التر ايكوجر اما المختبرة.

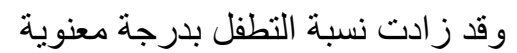

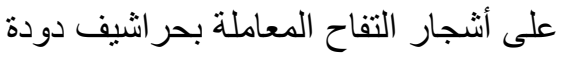

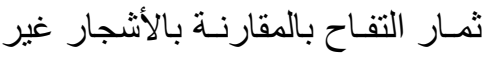


بيض هذه الآفة إلى 1.6 31.

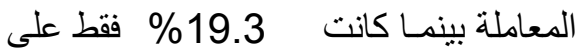
الأشجار غير المعاملة.
يعتبر الكيرومون الموجود بحر اشيف

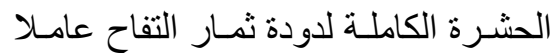

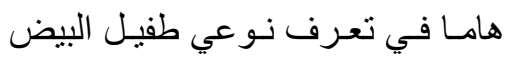
Trichogramma cacoeciae and $T$. dendrolimi

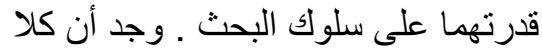

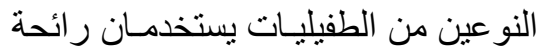

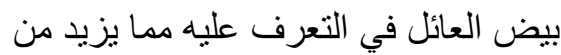

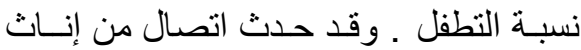
الطفيليـات ناتطبل

T. dendrolimi 1984, T. dendrolimi 1990 and T. cacoeciae 1990 غير المغسـول بالهكسـان بدرجة عالية

تحكيم: أ.د جورج نصر اللهرزق أ.د أحمد رؤوف حامد الهد 